\title{
Mast cells at sites of cartilage erosion in the rheumatoid joint
}

\author{
MICHAEL BROMLEY, ${ }^{1}$ WILLIAM D. FISHER, ${ }^{2}$ AND \\ DAVID E. WOOLLEY
}

From the ${ }^{1}$ University Department of Medicine, University Hospital Of South Manchester, Manchester M20 $8 L R$, and the ${ }^{2}$ Department of Orthopaedic Surgery, Western Infirmary, Glasgow G11 6NT

SUMMARY Cartilage-pannus junctions of the rheumatoid lesion have been examined by histochemical and ultrastructural techniques in an attempt to identify the cells responsible for cartilage degradation. Mast cells have been identified at sites of cartilage erosion in 3 specimens of rheumatoid joint. It is known that mast cells participate in immunological reactions, produce the vasoactive and proteinase-modulating agents histamine and heparin as well as their own degradative proteinases. The close association of mast cells with sites of cartilage erosion suggests they may play an important role in the pathophysiology of joint destruction in rheumatoid arthritis.

Mast cells are widely distributed in connective tissues and are found in increased numbers in lesions of immediate hypersensitivity and often in chronic inflammatory granulomata. Normal synovial membranes were reported to contain approximately $3 \%$ mast cells, ${ }^{1}$ and increased numbers have been reported in rheumatoid synovial specimens ${ }^{2}$ and in those from patients with juvenile rheumatoid arthritis. ${ }^{34}$ Although it has been suggested that mast cells may be important in the pathogenesis of connective tissue disease ${ }^{5}$ and allergic-inflammatory disease, ${ }^{6-9}$ there is surprisingly little information on the role of such cells in the pathophysiology of rheumatoid joints. Mast cells are readily identified by their large, metachromatic cytoplasmic granules, which contain heparin, histamine, proteinases, and various mediators and chemotatic factors. These components are released on degranulation or by carefully controlled exocytosis and are thought to have important functions in cell:cell interactions and tissue degradation associated with inflammatory disease. ${ }^{89}$

Because of our interest in the mechanisms of joint destruction in rheumatoid arthritis we have made a detailed histological study of specimens of cartilagepannus junctions to identify the types of cell found at the rheumatoid lesion. Of 37 specimens examined 17 had clearly defined cellular junctions which showed considerable variation in cellular type and distribu-

Accepted for publication 21 January 1983.

Correspondence to Dr D. E. Woolley, University Department of Medicine, University Hospital of South Manchester, Manchester M20 8LR. tion. Macrophages, polymorphonuclear leucocytes, and fibroblastic cells have all been demonstrated at junctional locations, but of particular interest was the identification of mast cells at sites of cartilage erosion, and this we report here.

\section{Materials and methods}

Specimens of cartilage-pannus junctions were obtained during therapeutic arthrotomy procedures from seropositive patients with classic rheumatoid arthritis.

\section{LIGHT MICROSCOPY}

Each specimen was fixed in $1 \%$ formaldehyde and $0.25 \%$ glutaraldehyde buffered with $0.1 \mathrm{M}$ sodium cacodylate $(\mathrm{pH} 7.4)$ and dehydrated in acetone. The tissue was embedded in JB-4 (Polysciences Ltd) at $4^{\circ} \mathrm{C}$ and $2 \mu \mathrm{m}$ plastic sections were cut with an LKB III ultratome. The sections were routinely stained with a mixture of $1 \%$ methylene blue and azure II in $1 \%$ borax. Various histochemical stains were used for the identification of specific cell types. Macrophages were positive for $\alpha$-naphthyl acetate esterase activity. ${ }^{10}$ Polymorphonuclear leucocytes (PMN) were identified by their positive reaction for naphthol-ASD-chloroacetate esterase and by nuclear staining with haematoxylin. ${ }^{112}$ Mast cells were positive for both naphthol-AS-aminocaproate esteras $^{13}$ and napthol-ASD-chloroacetate esterase staining, and were also identified by their distinctive granules stained with toluidine blue. Other cell types 
were identified by morphology and lack of response to the esterase stains employed.

Each cellular junction was classified according to the major identifiable cell type observed within 2-3 cell diameters from the cartilage interface.

ELECTRON MICROSCOPY

Rheumatoid specimens were fixed for $3 \mathrm{~h}$ in $1.5 \%$ glutaraldehyde buffered with $0 \cdot 1 \mathrm{M}$ sodium cacodylate $(\mathrm{pH} \mathrm{7.4)}$ and $3 \mathrm{mM} \mathrm{MgCl}$, followed by $1.5 \mathrm{~h}$ postfixation in $1 \%$ osmium tetroxide. After embedding in Epon 812 sections were cut with an LKB III ultratome. These were doubly stained with uranyl acetate and lead citrate and examined on an AEI Corinth electron microscope.

\section{Results and discussion}

Seventeen specimens had clearly defined cellular junctions, and most showed cartilage invasion by

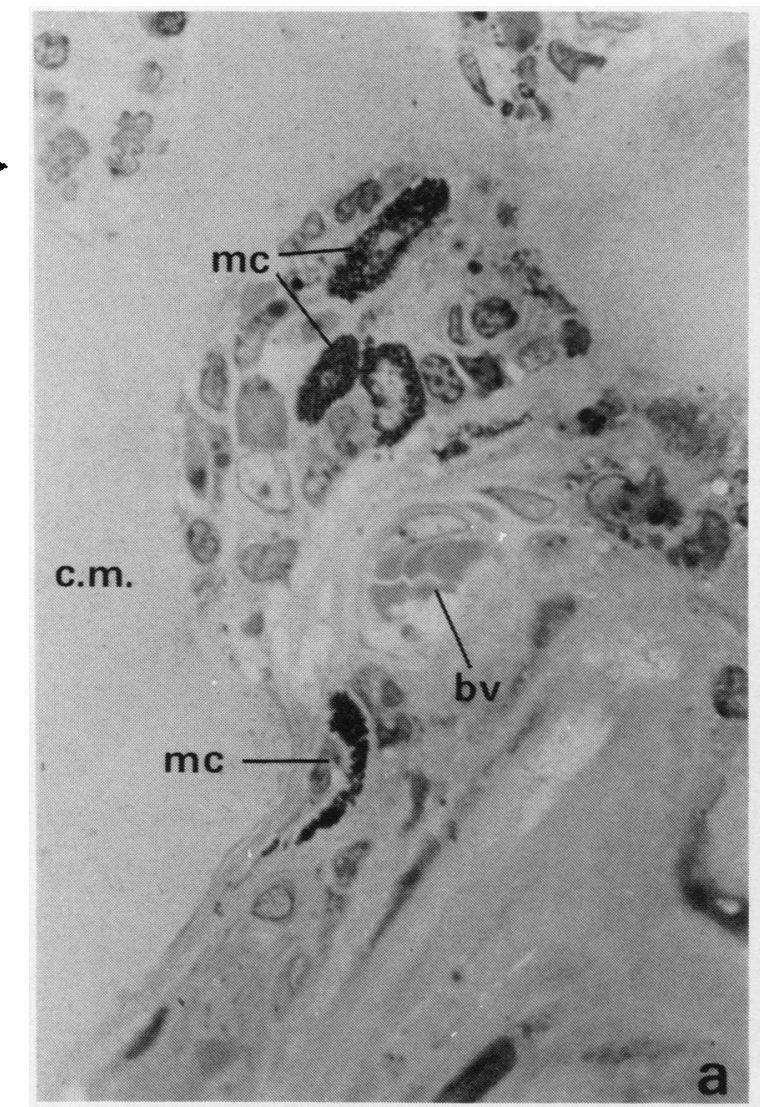

relatively avascular tissue containing fibroblastic and monocytic cells, similar to that described previously. ${ }^{14}$

Macrophages were the dominant cell type in 5 specimens, while polymorphonuclear leucocytes were observed in 2 others. However, the finding of 3 specimens with significant numbers of mast cells apparently concentrated at the cartilage interface is a new and interesting observation, especially as these cells were often located at sites which suggested newly formed pockets of matrix erosion.

The variable nature of our observations suggest that no constant pattern of specific cell infiltration exists at the cartilage-pannus junction, and we believe there is probably an intermittent turnover of inflammatory cells in this location. Thus the presence of mast cells observed in junctional specimens at the time of surgery probably represents a transient, and possibly cyclical, phase of the inflammatory process.

Fig. 1 shows mast cells at the cartilage-pannus

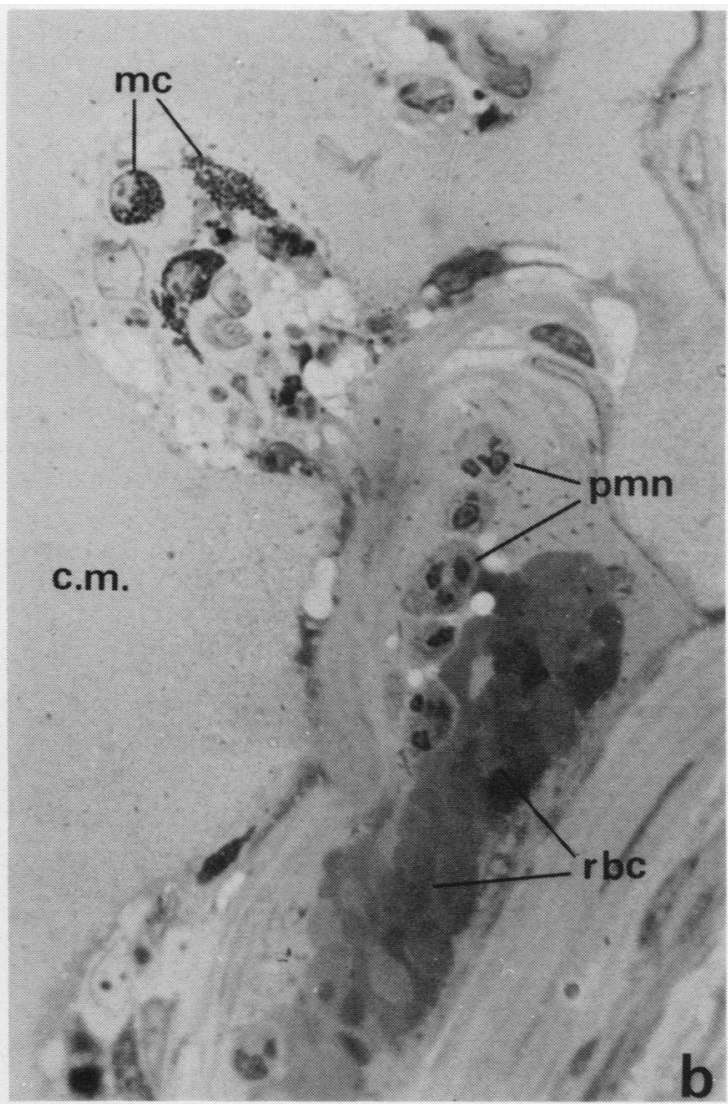

Fig. 1 Mast cells at the cartilage-pannus junction of a rheumatoid joint. (a) Mast cells $(\mathrm{mc})$ stained with methylene blue and azure II in close association with the cartilage matrix $(\mathrm{cm})$ and a small blood vessel $(\mathrm{bv})(\times 825)$. (b) Mast cells are recognised in a small pocket of cells which suggests localised erosion of the cartilage matrix. A larger blood vessel containing polymorphonuclear leucocytes $(\mathrm{pmn})$ and red blood cells $(\mathrm{rbc})$ is in close association. $(\times 825)$. 
junction of a rheumatoid joint. The mast cells were often observed in small pockets which suggested localised invasion of the cartilage. Small blood vessels were often in close association, but comparatively few mast cells were observed in synovial pannus tissue remote from the junctional region. The accumulation of polymorphonuclear leucocytes along the blood vessel wall adjacent to the mast cells in Fig. 1b is of particular interest, especially in relation to complement activation and the chemotactic and vasodilatory properties of mast cell-leucocyte interactions. $^{6}$

Ultrastructural studies of junctional regions have confirmed the presence of mast cells close to the cartilage matrix (Fig. 2). Such cells were well preserved with a characteristic rounded or oval nucleus and densely stained cytoplasmic granules. The granules were generally spherical in shape, and at higher magnification most were found to contain amorphous material with only a few containing crystalline structures.

Of the 3 specimens positive for mast cells at the junctional region one showed a particularly high incidence of such cells. Interestingly this patient had a very aggressive form of rheumatoid arthritis with early and severe cartilage and bone erosion, but no evidence was found for granulocytopenia, and skin biopsies revealed a normal distribution of mast cells.

The fact that the observations reported here have not been reported before could have several explanations. As most synovial specimens often represent advanced stages of the disease, it is possible that the cellular composition may be very different from that of early erosive lesions, and this is supported by the report that mast cells were the first to appear in excess in very early stages of rat adjuvant arthritis. ${ }^{15}$ Other explanations include the fact that mast cells tend to degranulate during histological procedures and are often inconspicuous in sections stained with conventional methods such as haematoxylin and eosin.

Recently Mohr and colleagues reported that about $25 \%$ of all rheumatoid specimens examined showed polymorphonuclear leucocytes at the cartilagepannus junctions; they were using nuclear staining with haematoxylin and naphthol-ASD-chloroacetate esterase staining as a cytoplasmic marker. ${ }^{11}{ }^{12}$ However, this histochemical staining technique is not specific for polymorphs, for it stains mast cells just as effectively. ${ }^{10}$ While we do not dispute that polymorphs may be detected at junctional sites, our findings are not in agreement with the frequencies reported by Mohr et al. ${ }^{12}$ One explanation could be that no allowance was made for the possible contribution of stained mast cells in their studies. Alternatively the type of specimen examined may be important, for whereas they have largely examined metacarpo- and metatarsophalangeal joints the majority of our specimens were derived from the knee.

It is known that the number of mast cells is increased in many forms of chronic inflammation, and that their interactions with $\mathrm{T}$ - and B-lymphocytes are probably involved at several levels of delayed hypersensitivity reactions. Mast cells have been reported to facilitate angiogenesis, probably through the release of heparin, ${ }^{16}$ and this may encourage the spread and overgrowth of invasive rheumatoid pannus tissue. As heparin has also been shown to stimulate the release of collagenase from cultured bone tissue,${ }^{17}{ }^{18}$ it might also have an important function in
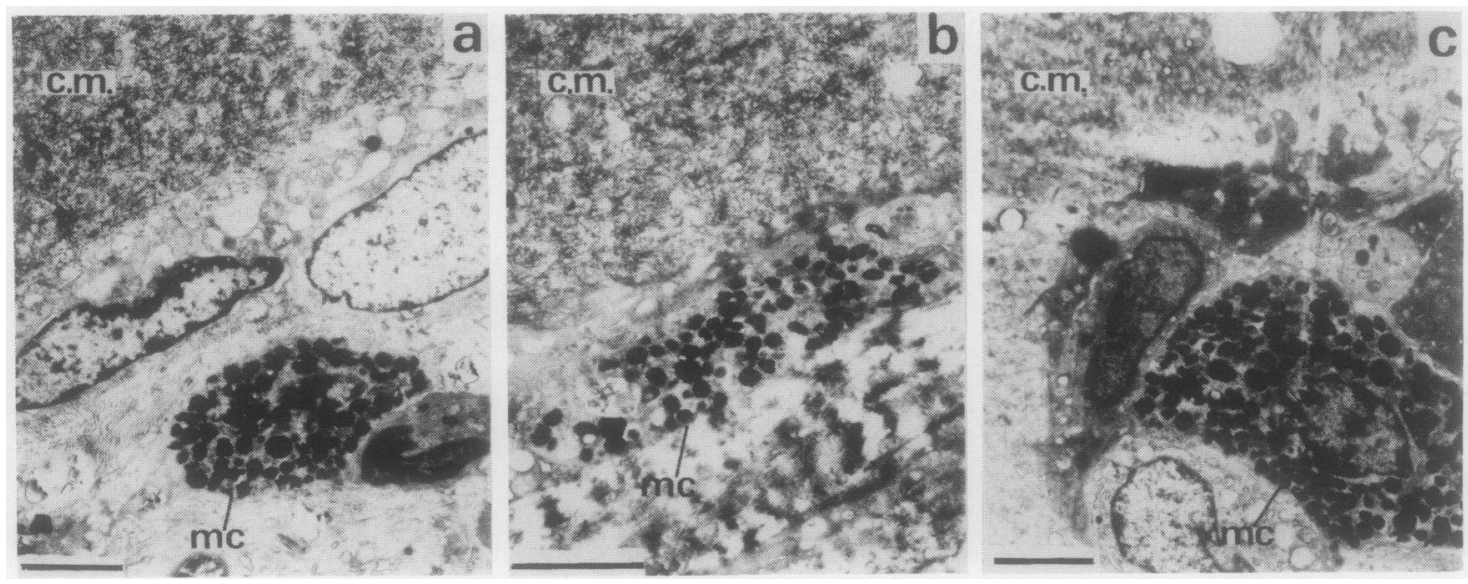

Fig. 2 Ultrastructural study of mast cells at the cartilage-pannus junction of rheumatoid joints. (a), (b), and (c) Electron micrographs showing mast cells $(\mathrm{mc})$ with densely stained cytoplasmic granules in close association with the cartilage matrix (cm). $($ Bar $=5 \mu \mathrm{m})$. 
regulating proteinase physiology at the rheumatoid lesion. This is of particular interest in relation to the immunohistochemical findings of collagenase ${ }^{19}$ and elastase $^{20}$ apparently concentrated at the cartilagepannus junctions of some rheumatoid specimens. Mast cell secretory granules are known to contain a variety of degradative enzymes such as the acid hydrolases and neutral proteinases, and these can probably degrade proteoglycans and collagen. ${ }^{9}$ While the acid hydrolases function primarily in the acidic environment of intracellular phagolysosomes, they may also have a local extracellular role in matrix degradation..$^{21}$

Histamine from mast cells has long been recognised as a potent mediator of inflammatory reactions, and its role in rheumatoid arthritis has recently been suggested by the clinical improvement of patients treated with $\mathrm{H}_{1}$ and $\mathrm{H}_{2}$ antihistamines. ${ }^{22}$ Human mast cells are reported to generate prostaglandin $\mathrm{D}_{2}$ after activation by $\mathrm{IgE}$, and its subsequent interaction with other inflammatory cells is thought to be an important factor for the mediation of local homoeostasis and inflammation by the leukotrienes. ${ }^{9}$

Thus there are many ways in which mast cells could exacerbate and modulate cartilage erosion-either by production of their own proteinases or by the stimulation or recruitment of other cell types. Their presence at sites of cartilage erosion suggests they can regulate local microenvironmental physiology by the production of various vasoactive, chemotactic, spasmogenic, and proteinase-modulating factors in response to certain local stimuli. Such mediators might well perpetuate chronic inflammation and stimulate the proteolytic involved in matrix degradation. Further studies are now required to investigate the role of the mast cell in rheumatoid lesions, especially with regard to its interaction with other synovial cells and proteinase physiology.

We thank Rosaleen Walker for excellent technical assistance and Professor L. T. Yam for his gift of naphthol-AS-aminocaproate. This work was supported by the Arthritis and Rheumatisim Council.

\section{References}

1 Castor C E. The microscopic structure of normal human synovial tissue. Arthritis Rheum 1960; 3: 140-51.

2 Hirohata K, Kobayashi l. Fine structure of the synovial tissues in rheumatoid arthritis. Kobe J Med Sci 1964; 10: 195-225.
3 Wynne-Roberts C R, Anderson C H, Turano A M, Baron M Light and electron microscopic findings of juvenile rheumatoid arthritis synovium: comparison with normal juvenile synovium. Semin Arthritis Rheum 1978; 7: 287-302.

4 Althreya B H, Moser G, Schumacker H R, Hanson V, Dahms B, Thompson D M. Role of basophils and mast cells in juvenile rheumatoid arthritis. In: Pepys J, Edwards A M, eds. The mast cell: its role in health and disease. London: Pitman Medical, 1979: 127-36.

5 Smyth C J, Gum O B. Mast cells in connective tissue diseases. Arthritis Rheum 1958; 1: 178-83.

6 Austen K F. Homeostasis of effector systems which can also be recruited for immunologic reactions. J Immunol 1978; 121: 793-805.

7 Pepys J, Edwards A M. In: Pepys J, Edwards A M, eds. The mast cell: its role in helath and disease. London: Pitman Medical. 1979.

8 Austen K F. Biologic implications of the structural and functional characteristics of the chemical mediators of immediatetype hypersensitivity. Harvey Lectures. Series 73. 1979; 93-161.

9 Lewis R A, Austen K F. Mediation of local homeostasis and inflammation by leukotrienes and other mast cell compounds. Nature 1981; 293: 103-8.

10 Yam L T, Li C Y, Crosby W H. Cytochemical identification of monocytes and granulocytes. Am J Clin Pathol 1971; 55: 283-90.

11 Mohr W, Wessinghage $\mathrm{D}$. The relationship between polymorphonuclear granulocytes and cartilage destruction in rheumatoid arthritis. $Z$ Rheumatol 1978; 37: 81-6.

$12 \mathrm{Mohr}$ W, Menninger H. Polymorphonuclear granulocytes at the pannus-cartilage junction in rheumatoid arthritis. Arthritis Rheum 1980; 23: 1413-4.

$13 \mathrm{Li} \mathrm{C} \mathrm{Y,} \mathrm{Yam} \mathrm{L} \mathrm{T,} \mathrm{Crosby} \mathrm{W} \mathrm{H.} \mathrm{Histochemical} \mathrm{characterisation}$ of cellular and structural elements of the human spleen. $J$ Histochem Cytochem 1972; 20: 1049-58.

14 Kobayashi I, Ziff M. Electron microscopic studies of the cartilage pannus junction in rheumatoid arthritis. Arthritis Rheum 1975; 18: 475-83.

15 Gryfe A, Sanders P M, Gardner D L. The mast cell in early rat adjuvant arthritis. Ann Rheum Dis 1971; 30: 24-30.

16 Taylor S, Folkman J. Protamine is an inhibitor of angiogenesis. Nature 1982; 297: 307-12.

17 Sakamoto S, Sakamoto M, Goldhaber P, Glimacer M J. Studies on the interaction between heparin and mouse bone collagenase. Biochim Biophys Acta 1975; 385: 41-50.

18 Lenaers-Claeys G, Vaes G. Collagenase, procollagenase and bone resorption. Effects of heparin, parathyroid and calcitonin. Biochim Biophys Acta 1979; 584: 375-88.

19 Woolley D E, Crossley M J, Evanson J M. Collagenase at sites of cartilage erosion in the theumatoid joint. Arthritis Rheum 1977; 20: 1231-9.

20 Menninger $\mathrm{H}$, Putzier R, Mohr W, Wessinghage D, Tillman $\mathrm{K}$. Granulocyte elastase at the site of cartilage erosion in rheumatoid synovial tissue. $Z$ Rheumatol 1980; 39: 145-56.

21 Schwartz L B, Austen K F. Enzymes of the mast cell granule. J Invest Dermatol 1980; 74: 349-53.

22 Permin H. Stahl Skov P, Geisler A, et al. Possible role of histamine in rheumatoid arthritis. Allergy 1981; 36: 435-6. 